\title{
Incidence of overt and covert neurological damage in children with sickle cell disease
}

\author{
P.C. Hindmarsh, ${ }^{1}$ M. Brozovic, ${ }^{2}$ C.G.D. Brook ${ }^{1}$ and S.C. Davies ${ }^{2}$ \\ Departments of ' $P a e d i a t r i c s$ and ${ }^{2}$ Haematology, Central Middlesex Hospital, London NW10 7NS, UK.
}

\begin{abstract}
Summary: We studied 25 patients with sickle cell disease (15 with $\mathrm{HbSS} ; 8$ with $\mathrm{HbSC}$ and 2 with $\mathrm{HbS}^{\circ}$ ) using neurological examination as a marker of overt and computed tomographic (CT) scan as a marker of covert neurological damage. Of the 25 patients, $5(20 \%)$ had evidence of cerebral infarcts on CT scan, but only 4 of these 5 patients had neurological signs. Neurological problems were only seen in patients with HbSS. We could not identify any haematological risk factors, but in this small group of HbSS patients a crisis rate greater than 1 per year of follow up was associated with a significant risk of neurological damage.
\end{abstract}

\section{Introduction}

The clinical course of sickle cell disease (SCD) is characterized by repeated crises the commonest being vaso-occlusive. These events may occur anywhere in the body but the most debilitating manifestations occur in the nervous system. ${ }^{1}$ They include cerebral infarction, subarachnoid haemorrhage, transient ischaemic episodes and spinal cord syndromes. ${ }^{2}$ Several investigators have studied the neurological complications of SCD but patients have been selected on the basis of neurological dysfunction. ${ }^{3,4}$ The overall incidence of covert, as opposed to overt, ischaemic cerebral damage, therefore, remains unclear.

Blood transfusion regimens to suppress haemoglobin $\mathrm{S}$ production have been employed to reduce mortality from cerebral sickling events but they are not without complications. ${ }^{5,6}$ Knowledge of the incidence of overt and covert neurological damage is essential in order that permanent handicap may be avoided and methods of preventing cerebral sickling utilized in an effective manner. The purpose of this study was to establish the incidence in a population of children with SCD and to define any predisposing risk factors.

\section{Methods}

Twenty-five children with SCD aged between 6 and 17 years were studied; 15 have sickle cell anaemia (HbSS),

Correspondence: P.C. Hindmarsh M.R.C.P., Paediatric Department, The Middlesex Hospital, Mortimer Street, London WIN 8AA, UK.

Accepted: 9 April 1987
Eight have HbSC and 2 have sickle cell thalassaemia $\left(\mathrm{HbS}^{\circ}\right)$. Children under the age of 5 were excluded from the study as they could not undergo computed tomographic (CT) scan without sedation. Parental consent was obtained and the study was approved by the Hospital Ethical Committee.

Patients underwent a full neurological history (with particular reference to such manifestations as convulsions or visual disturbance), clinical neurological examination and a CT head scan. The hospital records were reviewed with respect to precipitating and prodromal illness.

The EMI CT 1010S Scanner was used routinely and scans were interpreted by two neuroradiologists who were unaware of the clinical findings. In patients with overt neurological signs, a high resolution CT scan (GE8800) was performed.

Haematological variables [haemoglobin (Hb), PCV, MCV, MCHC, $\left.\mathrm{MCH}, \% \mathrm{HbF}, \% \mathrm{HbA}_{2}\right]$ and the number of admissions for SCD-related crises per year (vaso-occlusive, sequestration, aplastic) were compared between the group of patients with no neurological damage and those with. Student's $t$ test was used to test the significance between groups.

\section{Results}

Twenty-five children took part in both neurological and radiological aspects of the study. Five out of 25 $(20 \%)$ children had evidence of cerebral infarcts on CT scan but only 4 of the 5 had neurological signs on physical examination. All 5 children had sickle cell anaemia (HbSS). Details of these patients and their

The Fellowship of Postgraduate Medicine, 1987 


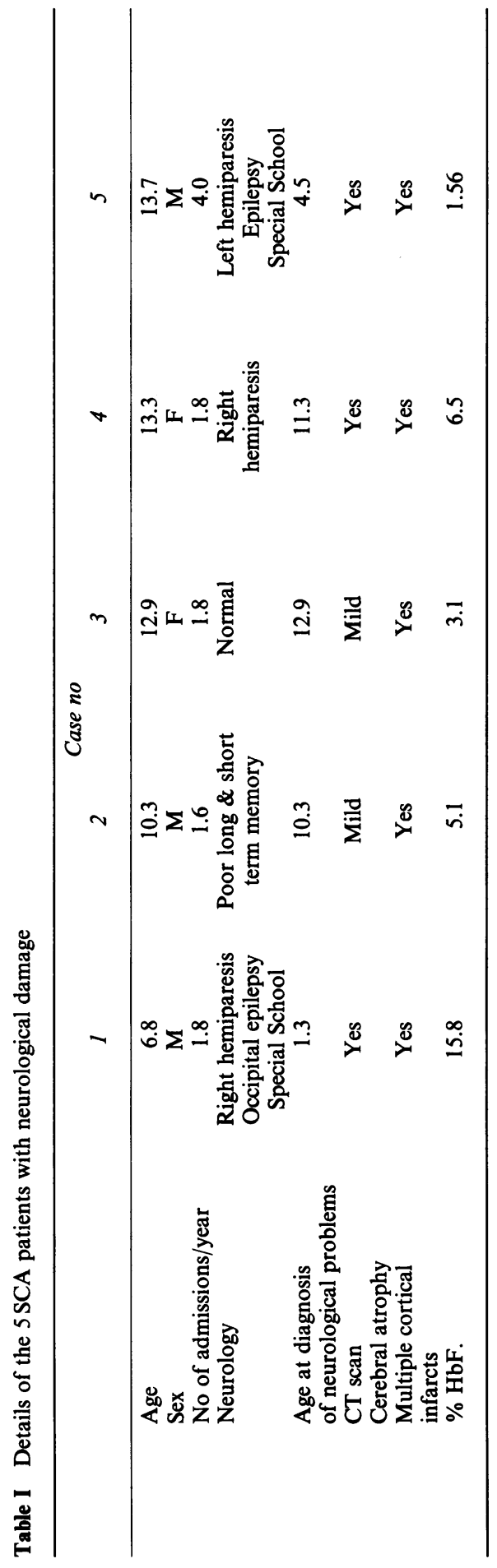

neurological and radiological findings are shown in Table I.

The CT scan abnormalities detected consisted of multiple cortical infarcts and cerebral atrophy. In cases 2 and 5 the cerebral atrophy was particularly marked (Figure 1). The majority of infarcts were in the watershed between the area supplied by the anterior and middle cerebral arteries.

There was no significant difference in haemoglobin, PCV, MCV, MCH, MCHC, $\mathrm{HbA}_{2}, \mathrm{HbF}, \alpha: \operatorname{non} \alpha$ globin chain synthesis ratio and platelet count between the groups of children with cerebral complications and those without. However, case 1 had a high $\mathrm{HbF}$, $14.8 \%$, at the time of his acute hemiplegia (age 16 months) which was probably age related.

The children without overt and covert neurological damage averaged 0.43 hospital admissions per year (range 0-1.2), while those with neurological damage experienced a greater number of hospital admissions for vaso-occlusive crises, 2.0 per year (range 1.0-4.0), prior to presentation with neurological complications. This difference was statistically significant $(P<0.001)$.

\section{Discussion}

This study has demonstrated a median age of onset from neurological problems of 6.8 years with neurological involvement in $20 \%$ of the clinic popula tion, confirming previous reports. ${ }^{2-4}$ In addition, we have demonstrated significant differences in admis? sion rates between the affected and non-affected groups. This difference may not be maintained in adult life $^{7}$ which may explain why Powars et al..$^{4}$ were unable to demonstrate any association with an increased crisis rate. It is also possible that our findings differed because the group studied by us were haematologically more homogeneous with the $\alpha$ thalassaemia interactions excluded. ${ }^{8,9}$

Decreased levels of $\mathrm{HbF}$ are thought to be a risk factor for the development of cerebrovascular disease in SCD. ${ }^{4,10}$ This relationship is not linear and a threshold level exists somewhere between 10-15\% $\mathrm{HbF}$ above which the risk is very low. ${ }^{11}$ Although the percentage $\mathrm{HbF}$ of those with neurological deficit was low the difference was not statistically significant from the other children studied. Other haematological variables were not of predictive value in patients with HbSS as has already been established. ${ }^{4}$

All patients with evidence of neurological deficit had SCA but neurological problems have been documented in patients where the $\beta$ gene interacts with other $\beta$ gene variants and $\beta$ thalassaemia such as HbSC disease. ${ }^{12}$ It is apparent, therefore, that a more sophisticated haematological assessment of these patients is essential particularly in view of the haematologically and genetically distinct forms of SCA seen in southern 


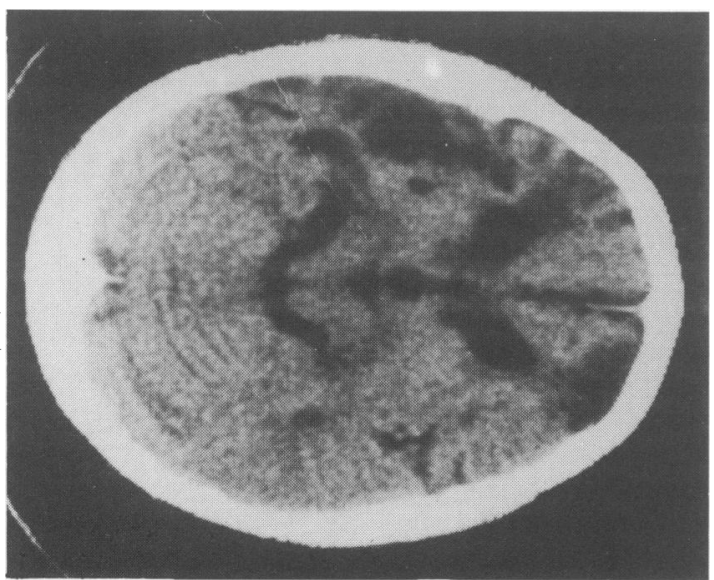

Figure 1 High resolution CT scan of Case 5 showing multiple cortical infarcts and cerebral atrophy.

and west Africa ${ }^{13}$ and also in Saudi Arabia. ${ }^{14}$

Our studies on this small group of children confirm that there is a high prevalence of overt and covert

\section{References}

1. Sydenstriked, V.P., Mulherin, W.A. \& Houseal, R.W. Sickle cell anaemia: report of two cases in children, with necropsy in one case. AJDC 1923, 26: 132-154.

2. Sarnaik, S.A. \& Lusher, J.M. Neurological complications of sickle cell anaemia. Am J Pediatr Hematol/Oncol 1982, 4: 386-394.

3. Portnoy, B. \& Heron, J.C. Neurological manifestations in sickle cell disease. Ann Int Med 1972, 76: 643-652.

4. Powars, D., Wilson, B., Imbus, C., Pegelow, C. \& Allen, J. The natural history of stroke in sickle cell disease. Am J Med 1978, 65: 461-471.

5. Sarniak, S., Soorya, A., Kim, J., Ravindranath, Y. \& Lusher, J. Periodic transfusion for sickle cell anaemia and CNS infarction. AJDC 1979, 133: 1254-1257.

6. Wilimas, J., Goff, J.R., Anderson, H.R. Jr, Langston, J.W. \& Thompson, E. Efficacy of transfusion therapy for one to two years in patients with sickle cell disease and cerebrovascular accidents. J Pediatr 1980, 96: 205-208.

7. Herold, S., Brozovic, M., Gibbs, J.M. et al. Measurement of regional cerebral blood flow, blood volume and oxygen metabolism in adults with sickle cell disease using position emission tomography. Stroke 1986, 17: 692-698.

8. Higgs, D.R., Aldridge, B.E., Lamb, J. et al. The interaction of alpha-thalassaemia and homozygous sickle cell disease. N Engl J Med 1982, 306: 1441-1446. neurological complications in patients with homozygous HbSS. In this subgroup high crises rate per year of follow up appeared to be associated with neurological damage. Acute hemiplegia seemed to be the major presentation in our group, as it is in children suffering with strokes in general. ${ }^{15}$ Patients with homozygous $\mathrm{HbSS}$ and high crisis rate should undergo regular neurological examinations at six monthly intervals with psychometric testing at yearly intervals. Implementing psychometric testing should reduce the need for regular CT scans but these are indicated if change is detected in any of the parameters already outlined. Blood transfusion regimens should be instituted promptly with the aim of keeping the \% HbSS below 15-20.

\section{Acknowledgements}

We would like to thank Drs B. Kendall and H. Shawdon for performing CT scans, Ms Elizabeth Anionwu (Head of the Brent Sickle Cell Centre) for patient liaison, Dr Anne Yardumian for constructive criticism and Miss Sarah Jewell for typing the manuscript. We also wish to thank our patients and their parents for their patience and co-operation.

9. Embury, S.H., Dozy, A.M., Miller, J. et al. Concurrent sickle cell anaemia and thalassaemia: effect on severity of anaemia. $N$ Engl $J$ Med 1983, 306: 270-274.

10. Russell, M.O., Goldberg, H.I., Hodson, A. et al. Effect of transfusion therapy on arteriographic abnormalities and on recurrence of stroke in sickle cell disease. Blood 1984, 63: 162-169.

11. Powars, D.R., Weiss, J.N., Chan, L.S. \& Schroeder, W.A. Is there a threshold level of fetal hemoglobin that ameliorates morbidity in sickle cell anemia? Blood 1984, 63: 921-926.

12. Fabian, R.H. \& Peters, B.H. Neurological complications of hemoglobin SC disease. Arch Neurol 1984, 41: 289292.

13. Nagel, R.L., Fabry, M.E., Pagnier, J. et al. Haematologically and genetically distinct forms of sickle cell anaemia in Africa: the Senegal type and the Benin type. N Engl J Med 1985, 312: 880-884.

14. Miller, B.A., Olivieri, N., Salameh, et al. Molecular analysis of the high haemoglobin of phenotype in Saudi Arabian sickle cell anemia. N Engl J Med 1987, 316: 244250.

15. Eeg-Olofsson, O. \& Ringheim, Y. Stroke in children. Clinical characteristics and prognosis. Acta Paediatr Scand 1983, 72: 391-396. 